\title{
Наталия Пятаева
}

Стерлитамакский филиал Башкирского государственного университета (Стерлитамак, Россия)

\section{ЭТИМОЛОГИЧЕСКОЕ ГНЕЗДО *DАТІ В ПРАСЛАВЯНСКОМ ЯЗЫКЕ: РЕКОНСТРУКЦИЯ, СЛОВООБРАЗОВАНИЕ, СЕМАНТИКА}

В статье представлено разноаспектное описание реконструированного этимологического гнезда (далее - ЭГ) с вершиной *dati применительно к праславянскому состоянию. С этой целью были использованы материалы словарей позднепраславянской лексики: «Этимологический словарь славянских языков» под редакцией О. Н. Трубачёва (ЭССЯ 1974 - 2014) и «Słownik prasłowiański» под редакцией Ф. Славского (SP 1974).

Праслав. глагол *dati продолжает и.-е. корень *dō- и заложенную в нём семантику: др.-инд. dā 'давать, дарить; выдавать замуж; продавать; выплачивать жалованье', (с удвоением корня) dádāti 'даёт', pradā- 'выдать замуж', dāvánē 'дать'; вед. dāváne 'дать', dadán 'я дал'; авест. (с удвоением корня) dadāiti 'даёт', dāvōi; перс. dadan 'дать'; арм. tam 'даю’, tamk 'даём'; алб.тоск. dhënё, dhąnё 'дар'; греч. (с удвоением корня) $\delta i ́ \delta \omega \mu 1, \varepsilon \chi \delta о \delta v \alpha \imath$ 'выдать замуж'; лат. dare 'дать', dō ‘даю'; умбр. purdouitu; др.-прусск. dāt(on); прусск. dāt(on), dātwei, dāst 'дать, позволить'; лит. dúoti, dúomi 'даю, дарю’, dovaná ‘подарок', išdúti ‘выдать замуж’; латш. duột, dãvãt ‘дать, давать', dâvana ‘подарок'; хеттск. того же корня, но с противоположным значением da 'брать', dahhi ‘беру’ (Гамкрелидзе, Иванов 1984: 41, 50, 171; Фасмер 1996, т. I: 367, 485; Черных 1994, т. I: 232).

Подчеркнём: в хеттском корень *dō- имел значение 'брать', один из глагольных дериватов др.-инд. dā - dāra означал 'брать в жёны, жениться’, следовательно, с достаточной долей уверенности можно утверждать, что в и.-е. значения 'давать' и 'брать' синкретично были соединены в одной словесной форме как универсальном обозначении обмена, занимающего важное место в праиндоевропейской картине мира. Подтверждением сказанному может служить наличие в большинстве и.-е. языков не только глагольных форм с корнем *dō- (примеры см. выше), но и древнейших именных производных на -no- и -ro: санскр. dāná, dānam 'дар, дарение; пожертвование; оплата, уплата; подкуп, 


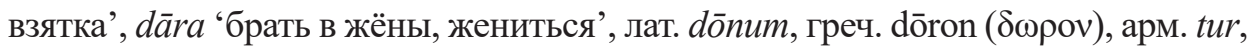
слав. darŭ (даръ). При всех своих сходствах и различиях эти формы хорошо сохранили древнее чередование [-r-/-n-] - «маркер архаичного типа склонения, называемого гетероклитическим, которое часто обнаруживается благодаря сосуществованию производных на -r- и -n-. Более того, в греческом имеется ряд именных форм, различающихся только способом словообразования, все они обозначают 'дар'. Это греч. 1) dốs ( $\delta \omega ́ \varsigma), 2)$ dōron $(\delta \omega \rho о v), 3)$ dōreá

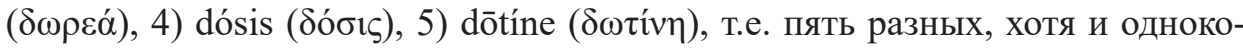
ренных, слов, которые одинаково переводятся как 'дар'» (Бенвенист 1995: 62-64).

Однако эти слова нельзя считать абсолютными синонимами: они обнаруживают общность лишь концептуального ядра лексического значения, каковым является сема 'дар - то, что даётся', различаясь оттенками и условиями употребления:

1. dốs ( $\delta \dot{\omega} \varsigma)$ 'приданое' - дар, приносимый супругой или дар будущего супруга для выкупа невесты; дар как средство установления выгодных отношений;

2. dōron ( $\delta \omega \rho о v)$ - 'дань', 'дар как материальный предмет, подарок';

3. dōreá ( $\delta \omega \rho \varepsilon \alpha ́)$ - 'акт приношения даров, дани';

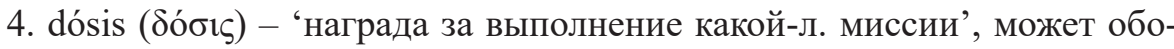
значать также юридический акт передачи наследства по чьему-л. волеизъявлению помимо правил обычного наследования; употребляется как медицинский термин, означая дачу лекарства, отсюда количество данного лекарства - доза;

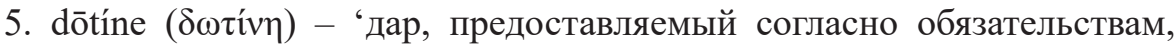
накладываемым соглашением, дружбой, гостеприимством’ (Вейсман 1991: 358-360).

Эта особенность и.-е. корня *dō- продолжается и в праславянском языке, где в составе ЭГ с вершиной *dati выделяются четыре семантико-словообразовательных центра: глагольный *dati и три именных *danь, *darъ и *datja. Чтобы восстановить семантический архетип каждого из указанных этимонов, проследим за их соответствиями в славянских языках.

1) *dati, *damь, *dadQtь, *dadętь 'дадут', *davati, *dajati, dajQ: ст.-слав. Аати, Аамь, АадАТ'b, Ааст'ъ, Аавати 'дать; вознаградить; позволить', болг. дам (се) 'дамся', да́вам; макед. дава 'давать, отдавать, причинять'; с.-х. дӓти (се), дам(се), да́вати(се) 'дать'; словен. dati, dam, dajati, dávati 'дать'; чеш. dáti, dám 'дать', dati se 'приняться, взяться', dávati, dávati se 'приниматься; словац. dat', dám 'дать; причинить беспокойство; уделять внимание', davat'; польск. dač, dam 'дать', dawač, daje; в.-луж. dać, dam, 'дать, разрешить, допустить', dawać, dawan; н.-луж. daś, dam 'дать, допускать', dawaś; полаб. dot 'дать'; др.-русск., русск.-цслав. дати 'дать; позволить', даватн; укр. да́ти(ся), дава́ти(ся); блр. дащ̧ь, да́щйа, дава́иь, дава́щйа 'дать, давать’; 
2) *danь (родственно др.-инд. dānam 'дар, пожертвование', алб. dhënё 'дар', лат. dōnum 'дар, подарок; жертва, жертвоприношение'): ст.-слав. дань 'налог, дань, подать'; болг. дан (да́нък) 'дань, подать, налог'; с.-х. дан 'дань', да́нак (пода̂ћa) 'поминки, тризна'; словен. dân(j) 'дань, налог, подать'; чеш. daň 'подать, повинность'; словац. daň 'налог, подать'; польск. dań, danina 'дань, подать, повинность; дар, подарок'; в.-луж. dan̆ 'подать, налог, повинность'; н.-луж. dań 'дар, подать, пошлина', dank 'налог'; др.-русск., русск.-цслав. дань 'дар; доход; подать, дань, подданство'; русск. дань 'подать, налог, которые взимались победителем с побеждённого племени, народа или князем со своих подданных; приношение, дар'; русск. диал. дань 'земельный надел до революции 1917 г.'; укр. дань (дани́на); блр. даніна 'дань';

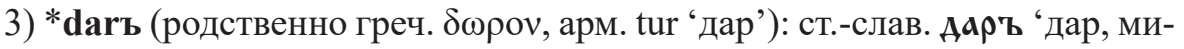
лость; вознаграждение, награда', даровати 'дарить, подарить'; болг. и макед. дар 'дар, подарок'; с.-х. да̂p 'дар, подарок', диал. да̂p 'подарки невесты свадебным гостям'; словен. dâr (davek, dajatev) 'дань, налог'; чеш. и словац. dar 'налог; дар, подарок, приношение'; польск. dar 'дар, подарок, приношение'; в.-луж. и н.-луж. dar 'дар, подарок’; др.-русск., русск.-цслав. даръ 'дар, подарок; склад; подать', дары ‘брачное приданое'; русск. дар 'подарок, подношение, пожертвование; способности, талант'; укр. дар (дару́нок) 'дар, даяние; дарование, талант'; блр. дар 'приношение, дар, подарок’;

4) *datja: болг. да́ча (ви́ла) 'загородный дом’; с.-х. да̂ћa ‘поминки’, дӓћа 'удача', dáћa 'дача взаймы, заём; подать, пошлина'; словен. dáča 'подать, дань'; др.-русск. дача 'дарованная князем земля’; русск., укр. и блр. да́ча 'принесение в дар', (позднее) 'загородный дом' (Дворецкий 1976: 347; Старославянский словарь 1999: 183, 184; Фасмер 1996, т. I: 480, 484-486; Черных 1994, т. I: 232; ЭССЯ, вып. 4: 188, 195-200; вып. 9: 23).

Таким образом, с достаточной долей вероятности, можно предположить, что концептуальным ядром семантики праслав. *dati, *damь являлось значение 'дать, отдавать' (процесс передачи объекта другому лицу), *danь - 'дань, подать' (объект обязательной передачи в качестве выкупа, платы, налога), *darъ - 'дар, подарок' (объект добровольной передачи в качестве подарка, вознаграждения, милости), *datja - nomen acti ‘даяние, принесение в дар'.

Сохранение в праславянском и современных славянских языках древних именных производных от одного корня, обозначающих 'дар' и 'обмен дарами, подарками' (*danь, *darъ), можно объяснить тем, что, согласно выводам В. В. Иванова (Иванов 1975), на определённом этапе раннего средневековья обмен и договоры как универсальные социологические явления принимали характер обмена подарками. По форме эти дары были добровольными, по существу же - строго обязательными. В результате устанавливалась тесная связь: на последнего - дарующего - налагались обязательства по отношению к первому - одариваемому. Таким образом, обмен дарами имел в глазах этих людей магическую силу, он представлял собой одно из средств социальных 
связей, наряду с браками, взаимными услугами, жертвоприношениями и культовыми действиями. Во всех этих формах также осуществляется обмен между племенами, семьями и индивидами, либо между людьми и божествами. Обмен дарами служил средством поддержания регулярных контактов в обществе между составлявшими его группами.

Понимание дара как акта, предполагающего взаимный обмен, позволяет объяснить наиболее характерную черту и.-е. корня *dō-, проявляющуюся в наличии у его производных конверсных значений - 'давать' (в большинстве и.-е. языков, в том числе в славянских, как видно из приведённых выше примеров) и 'брать' (в анатолийской группе и.-е. языков). Архаичность третьего именного производного *datja с семантической стороны удостоверяется такими значениями, сохранившимися в некоторых современных славянских языках, как с.-х. дӓћа 'поминки', словен. dáča 'подать', укр. дача 'принесение в дар', др.-русск. дачька 'дар' (ср. совр. русск. подачка) и дача 'дарованная князем земля'. Закономерным в этой связи представляется реконструируемое в качестве общеславянского префиксальное производное *pro-dati 'продать', находящее соответствия в др.-инд. pra-da 'отдавать, выдавать замуж' и вед. párā-dā 'кого-н. отдавать за определённую цену', которое можно считать «развитием значения термина, обозначающего первоначально обмен дарами, в частности, свадебными, а позднее куплю-продажу или денежные операции» (Иванов 1975: 59).

Представление о Боге как дарителе благ, согласно гипотезе Р. О. Якобсона (Якобсон 1963), отражено в имени др.-русск. Дажьбога, ср. ст.-польск. dadzibog; др.-русск. Аажьвог"Ъ (И поставн күмнры на Холму вн' двора теремнаго: Перуна ... и Хърса Дажьвога и Отрнгога. Пов. вр. л. под 980 г.) (ЭССЯ 4: 182-183). Многие исследователи (Афанасьев 1995; Иванов, Топоров 1991; Иванов 1975 и др.) обращали внимание на несомненную древность сочетания глагола *dati с именем сущ. *bogъ в качестве субъекта действия, ср. общеславянские сочетания этого типа, лежащие в основе таких речений, как с.-х. Бог је стариј давалеи, русск. Бог дал живот, Бог даст и здоровье; Бог даст день, Бог даст и пищу; Вам Бог дал, а нам посулил; Бог даст, и в окошко подаст; Бог дал, Бог взял и т.п. Наименование Дажьбога означает бога дающего (dues dator) - имя, которое очень подходит к солнцу или огню: И посемъ царствова сынъ его нменемъ Волнце, егО жЕ нарнчютъ ДажьБогъ... Эолнце царь сынъ Яварог"ъ єже єсть ДажьБогъ, в' во мужь снленъ (Хроника Малалы). Дажьбог, очевидно, является русским локальным обозначением Сварога, который прежде всего давал урожай на полях, имевший в жизни древних славян решающее значение, это Бог дающий, податель земных благ, а также Бог, охраняющий свой род. Он дал человеку всё главное (по космическим меркам): солнце, тепло, свет, движение (природы или календарное - смену дня и ночи, времён года, лет и т.д.), 
все земные блага, богатство, счастье, благополучие. Вероятно, Дажьбог был больше, чем Бог солнца, он обозначал то, что мы называем весь бельй свет. К тому же, как и все родовые боги, нёс светлое, творческое мужское начало, небесное начало, в отличие от тёмного, женского, рождающего, земного. Метафорически его называют огонь Сварожич. Сварог - Бог неба (как космоса), значит Дажьбог - свет небесный. Удостоверяемое этими данными обозначение Бога как дарителя, с одной стороны, соответствует его же обозначению как гостя, получающего дары, с другой стороны, отвечает всей реконструируемой на основе рассмотренных терминов системы взаимных обменов дарами.

Итак, можно констатировать, что концептуальное ядро семантики праславянской лексики ЭГ *dati образует значение 'дать, отдавать в пользование, давать в качестве платы, подарка, даров’, которое является основой семантической и словообразовательной деривации. По данным (ЭССЯ и SP 1974) для праславянского уровня реконструируется 153 лексемы, занимающие (в соответствии с семантической и словообразовательной производностью) строго определённое место в составе ЭГ с вершиной *dati. Рассмотрим более подробно состав производных каждого из четырёх упомянутых выше семантико-словообразовательных центров.

1. Семантико-словообразовательный центр *dati 'дать, отдавать' (процесс передачи объекта другому лицу), содержит 109 производных (71\% от общего количества слов ЭГ), среди которых представлены: 25 возвратных глаголов: *datisę, *izъdatisę, *izъdavatisę, *nadatisę, *obdatisę, *orzdatisę и др.; вторичный инфинитив, обозначающий длительное действие, *dajati с производным *dајьпъјь; имперфектив *davatiт и 13 его префиксальных производных: *izъdavati, *nadavati, *obdavati, *orzdavati, *otъdavati, *podavati, *podъdavati, *prědavati, *pridavati и др.; три вариантных страдат. прич. пр. вр. *dadenъ, *danъ, *datъ, имеющих дериваты nomen patientis: *danъ 'данный' $\rightarrow$ *danьје 'даяние, подать; наследство; приданое', *datъ 'данный' $\rightarrow$ *datъkъ 'то, что дают; подать; налог, подарок; вознаграждение; сдача', *datъ 'данный' $\rightarrow$ *datьje 'дар, подарок, пожертвование'; префиксальные глаголы, их имперфективы и возвратные дериваты: *jьzdati(sę), *jьzdavati(sę), *nadati(sę), *nadavati(sę), *obdati(sę), *obdabvati(sę), *orzdati(sę), *orzdavati(sę), *otъdati(sę), *otъdavati(sę), *podati(sę), *podavati(sę), *podъdati(sę), *podъdavati(sę), prědati(sę), *prědavati(sę), *pridati(sę), *pridavati(sę), *prodati(sę), *prodavati(sę), *sъdati(sę), *sъdavati(sę), *vъdati(sę), *vъdavati(sę), *vъzdati(sę), *vъzdavati(sę), *zadati(sę), *zadavati(sę); сущ. nomen agentis: *davačь, *davьсь // *davьca, *datelь, *podatelь // *podaditelь; сущ. nomen patientis: *davъka // *davъkъ // *davъky, *nadavъkъ, *danьje, *datъkъ, *datьje, *dadje, *dara, *datь, *nadatъkъ, *prodadja; имена прилаг.: *dajьnъјь, *danьnъјь, *danьskъ, *dasnь, *dativъјь, *datьnъ $($ јь $) \rightarrow *$ nedatьnъ $($ јь $)$; имя собственное: *bogodanъ//*bogъdanъ (ср. русск. Богдан). 
2. Семантико-словообразовательный центр *darъ 'дар, подарок как объект добровольной передачи в качестве подарка, вознаграждения, милости' содержит 32 производных (21\%), которые представлены: глаголом действия *dariti и его дериватами: *daritisę, *darovati (имперфектив-перфектив); сущ. nomen acti: *darina, *darьba, *darıstvo; сущ. nomen agentis: *daritelь //*darovatelь, *darımьnikъ, *darьmojědъ //*darьmojěda (именное сложение наречия с основой глагола *jědmь, *jěsti), *darьnikъ, *darovьnikъ, *bezdarъ; сущ. nomen patientis: *darъkъ //*darikъ //*darьсь, *darъje; сущ. nomen collectivum: *darьje 'свадебные подарки'; прилаг:: *darežьnъ(јь), *darьmovъ, *darьmьnъ, *darъјь $\rightarrow$ *nedarъjь, *darovitъ(jь), *darovъ, *darovьnъ, *darьnъ(јь) $\rightarrow$ *nedarьnъ(jь); отглагольными наречиями: *darьmo, *darьma, *darьmъ; именем собственным: *bezdarъ 'не имеющий или не получающий даров, их не дающий'.

3. Третий семантико-словообразовательный центр *danь 'дань, подать как объект обязательной передачи в качестве выкупа, платы, налога', имеющий 9 производных (6\%), представлен: сущ. nomen acti: *danьnica 'акт дарения'; сущ. nomen agentis: *danьnikъ; сущ. nomen patientis: *danina, *danъkъ, *danьје 'подать; наследство, приданое'; прилаг.: *danьnъјь, *danьskъ; именем собственным *daniborъ.

4. Четвёртый семантико-словообразовательный центр *datja (nomen acti 'даяние, принесение в дар') представлен одним префиксальным производным с противоположным значением *nedatja 'то, что не дано, не отдано; неудача, несчастье, беда'.

Продуктивные словообразовательные типы, характеризующие описываемое ЭГ, образуют систему на основе семного состава лексического значения вершины гнезда - глагола *dati, который обозначает действие передачи объекта другому лицу. В рассматриваемом ЭГ представлены следующие способы словообразования:

- суффиксация - 113 дериватов, что составляет 74\% от общего количества слов гнезда, например: *dati-sę, *daj-ьnъ-jь, *da-va-ti, *dav-ačь, *nadav-ъkъ//*nadav-ъka, *da-jь//*da-ja, *da-nь, *da-ra, *da-rъ, *dar-i-ti, *dar-ьba, *dar-ovati;

- префиксация - 32 деривата (21\%), например: *na-davati, *ne-darъjь, *ne-darь-nъjь, *bez-darъ, *ne-da-tja, *izъ-dati, *jьzъ-dati, *na-dati;

- сложение основ - 4 деривата $(2,6 \%)$ : *dadjь-bogъ, именное сложение наречия с основой глагола *jědmь, *jěsti - *darьmo-jědъ//*darьmo-jěda 'лентяй, тунеядец' и имена собственные *bogo-danъ//*bogъ-danъ (Богдан), *daniborъ (Данибор).

Среди производных праслав. *dati отмечается следующее распределение слов по частеречному признаку:

- глаголов - 69 (45\% от общего числа слов), в числе которых представлены: 19 префигированных производных, обозначающих различные действия передачи, например: *na-dati, *na-davati 'много дать; дать в несколько приёмов; удлинять, наращивать, надставлять', *jьzъ-dati ‘издать запах, звук; отдать, 
выдать, предать', 15 имперфективов, например: *izъda-va-ti, *nada-va-ti, *obъda-va-ti, *otъda-va-ti, *poda-va-ti, 3 особые формы: вторичный инфинитив несовершенного вида *dajati 'давать', тематизированный глагол *dar-i-ti 'дарить, приносить в дар; награждать, жаловать', имперфектив-перфектив *dar-ova-ti ‘даровать; делать свадебный подарок; подавать нищему; прощать, извинять';

- существительных - 59 (39\%), они обозначают: название действия передачи, дарения, продажи, выплаты: *da-jь // *da-ja, *jьzda-ja, *prěda-jь, *proda-jь, *vyda-jь, *da-nьje, *danь-nica, *dar-ьbа; имя деятеля - 'тот, кто даёт, податель; данник, тот, кто платит; даритель’, например: *dava-с̌ь, *danь-nikь, *dari-telь // *darova-telь, *darь-nikъ; наименование объекта действия передачи 'то, что дают, дарят, продают; дань, подарок': *dav-ъka // *dav-ъkъ // *dav-ъky, *nadav-ъkъ // *nada-vъka, *danь-je, *dat-ъkъ, *da-tьje, *da-dje, *daпь, *da-nina, *da-ra, *da-rъ; имена собственные: *dadjь-bogъ, *bogъ-danъ, *dani-borъ, *bez-darъ;

- прилагательных - 17 (11\%): *daj-ьnъјь, *darež-ьnъ(jь), *dar-ъjь, *darovit-ъ(jь), *dar-ьnъ(jь), *da-snь // *da-snъ, *dat-ьnъ(jь) 'обильный, щедрый; богатый (об урожае); даровитый, способный (о человеке)' и их антонимические префиксальные производные *ne-darъjь, *ne-darьnъjь 'скупой, скудный, не уродившийся (о хлебе), бесплодный; неудачный, нездоровый’, *nedatь-nъ(јь) 'скупой; неудачный, несчастный; проклятый'; *dan-ьnъјь, *dan-ьskъ 'относящийся к дани, податной'; *dar-ьmovъ 'дармовой, бесплатный’, *dar-ьтьпъ 'дарованный, бесплатный’, *dar-ovъ 'даровой', *dar-оvьпь 'дарованный'; *dat-ivъјь 'способствующий, служащий';

- одно наречие (0,7\%) - *dar-ьmo // *dar-ьma // *dar-ьmъ ‘даром; напрасно', однако довольно продуктивное в семантико-словообразовательном отношении - в структуре ЭГ *dati оно имеет три производных: *darьm-ovъ 'дармовой, бесплатный', *darьm-ьnъ 'дарованный, бесплатный', *darьmo-jědъ // *darьmo-jěda.

Подводя итог реконструкции и разноаспектному рассмотрению ЭГ *dati на праславянском уровне, можно отметить наиболее важные разноуровневые явления.

1. Формальные характеристики праславянской лексики - распределение по частям речи, способы словообразования, представленные в ЭГ, их процентное соотношение - в основном соответствуют формальным и относительным количественным характеристикам продуктивных глаголов в русском языке XI-XVII вв. и современном русском языке. Самым распространённым способом словообразования неизменно является суффиксация, вторым по значимости - префиксация. Поскольку рассматриваемое праславянское гнездо и его рефлексы возглавляются глаголами, обладающими широкими возможностями в присоединении приставок и суффиксов, то закономерно преобладающей частью речи в гнёздах являются глаголы, на втором месте представлены имена существительные, гораздо менее численными являются имена прилагательные и наречия. 
2. Фиксируемые на праславянском уровне в ЭГ *dati четыре семантикословообразовательных центра: глагольный *dati и три производных от него именных *danь, *darъ, *datja - в дальнейшей судьбе рассматриваемого лексического гнезда претерпели существенные семантические преобразования и деэтимологизировались, т.е. выделились в самостоятельные словообразовательные гнёзда с вершинами дань, дар, дача (см. данные словообразовательного словаря А. Н. Тихонова (Тихонов 1985, т. 1).

3. По данным современных исследователей (Бернштейн 1972; Трубачёв 1991; Рыбаков 1994), праславянский период охватывает поздний неолит (25-17 вв. до н.э.), бронзу (17-7 вв. до н.э.) и железо (от 7-го в. до н.э.), завершается он во второй половине первого тысячелетия н.э., когда славяне уже занимали значительную территорию Средней, Восточной и Южной Европы, когда далеко зашёл процесс феодализации, приведший к формированию ранних славянских государств. В эпоху железа славяне достигли сравнительно высокого уровня экономического развития. На смену первобытнообщинному строю постепенно приходил новый строй, коренным образом изменивший социальную структуру старого общества. Разделение труда привело к интенсивному развитию ремёсел, формированию городов, выделению военного сословия и сословия волхвов - организаторов культурной жизни народа. На рубеже до-христианской и христианской эры славянское язычество представляло собой сложную и разветвлённую систему, далеко ушедшую от древнейших форм раннего язычества. Все эти изменения отразились на языковом оформлении праславянской картины мира, а словарь этимологического гнезда, в частности, *dati, позволяет проследить формирование языковой картины мира в динамике и выявить следующие сферы жизни и деятельности «праславянина»:

- торговля: *nadavъkъ ‘доплата', *davačь ‘податель', *dајьпъјь ‘щедрый’, *izdati 'дать взаймы', *nadavati 'даровать, наделить правом владения’, *prodati 'продать';

- свадебный обряд, семейные отношения: *davati 'выдавать замуж', *jьzdati ‘выдать замуж’, *danьје 'наследство, приданое', *obdariti ‘принести свадебные дары';

- хозяйственно-бытовые и государственные отношения: *davъka 'налог, подать, дань', *izъdati 'дать взаймы', *nadavati 'даровать, наделять правом владения', *nadavъkъ и *nadatъkъ 'доплата, дополнительный надел земли', *obdavati 'раздавать милостыню', *orzdati 'выдать всё, разделить между всеми', *podatja 'милостыня';

- сельское и домашнее хозяйство: *danьје 'наследство, приданое', *darımovъ 'дармовой', *darьmьnikъ 'работник, выполняющий работу без оплаты', *darьmojědъ 'лентяй, тунеядец', *obdati и *zadati 'задать корм скотине', *neudatja 'неудачно испечённый хлеб', *nedarъјь 'скудный, неуродившийся (о хлебе)'; 
- военное дело: *otъdati 'проиграв сражение, оставить неприятелю город', *podъdatisę и *sъdatisę 'признать себя побеждённым', *prědati 'изменнически выдать';

- религия и мифология: *udatja 'удача, везение', *vъzdatisę 'воздаться (о вознаграждении или возмездии)', *nedatьnъјь 'несчастный, проклятый', *dadjьbogъ - Дажьбог.

Автор надеется, что реконструированное в виде словообразовательного словаря ЭГ и представленный в статье анализ этого гнезда, а также заданная им схема (матрица) подобного разноаспектного исследования и описания крупных лексических объединений могут сыграть немаловажную роль в системном взгляде на динамику формирования картины мира носителей языка, ибо, по справедливому замечанию О. Н. Трубачёва, «словарь, сравнительно с текстом, даёт конденсированный характер отражения языковой картины мира» (Трубачёв 2002: 20).

\section{Библиография}

Афанасьев А. Н. (1995), Происхождение мифа, метод и средства его изучения, [в:] Поэтические воззрения славян на природу: в 3-х m, Москва, т. 1, с. 5-29.

Бенвенист Э. (1995), Словарь индоевропейских сочиальных терминов, Москва.

Бернштейн С. Б. (1972), Из истории славянского cyффикса -telb, [в:] Русское и славянское языкознание, Москва, с. 36-42.

Вейсман А. Д. (1991), Греческо-русский словарь, Москва.

Гамкрелидзе Т. В., Иванов В. В. (1984), Индоевропейский язык и индоевропейцы. Реконструкция и историко-типологический анализ праязыка и протокультуры, ч. I-II, Тбилиси.

Дворецкий И. Х. (1976), Латинско-русский словарь, Москва.

Иванов В. В. (1975), Происхождение семантического поля славянских слов, обозначающих дар и обмен, [в:] Славянское и балканское языкознание. Проблемы интерференции и языковых контактов, Москва, с. 50-78.

Иванов В. В., Топоров В. Н. (1991), Дажьбог, [в:] ред. С. А. Токарев, Мифы народов мира. Энииклопедия: в 2-х т., Москва, т. 1, с. 347.

Рыбаков Б. А. (1994), Язычество древних славян, Москва.

Старославянский словарь (по рукописям X-ХІ веков) (1999), ред. Р. М. Цейтлин, Р. Вечерка, Э. Благова, Москва.

Тихонов А. Н. (1985), Словообразовательный словарь русского языка: в 2-х т., Москва.

Трубачёв О. Н. (1991), Этногенез и культура древнейших славян. Лингвистические исследования, Москва.

Трубачёв О. Н. (2002), Опьтт ЭССЯ: к 30-летию с начала публикации (1974-2003), «Вопросы языкознания», № 4, с. 3-24.

Фасмер М. (1996), Этимологический словарь русского языка: в 4-х т., Санкт-Петербург.

Черных П. Я. (1994), Историко-этимологический словарь русского языка: в 2-х т., Москва.

ЭССЯ - Этимологический словарь славянских языков. Праславянский лексический фонд (1974-2014), ред. О. Н. Трубачёв, Москва, вып. 1-39.

Якобсон Р. О. (1963), Типологические исследования и их вклад в сравнительное языкознание, «Новое в лингвистике», вып. 3, с. 95-106.

SP - Słownik prasłowiański (1974), red. Fr. Sławski, Wrocław, Warszawa, Kraków, Gdańsk, т. I. 


\section{Список сокращений}

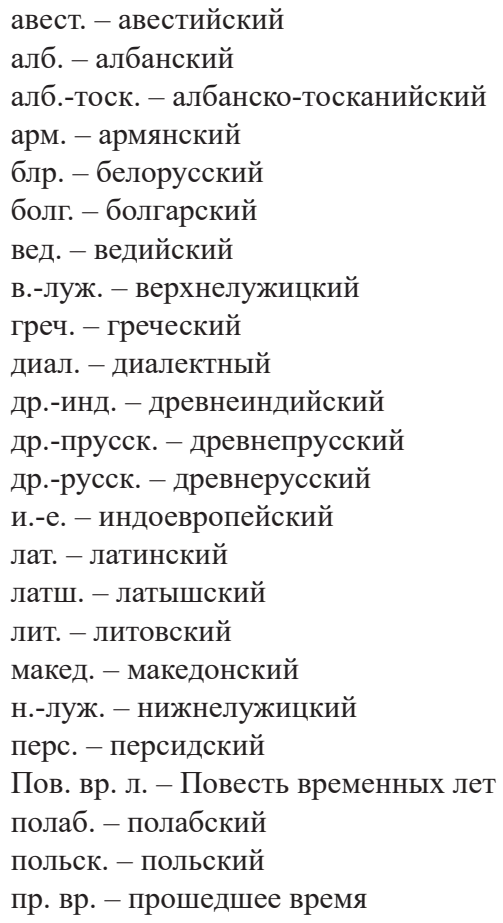

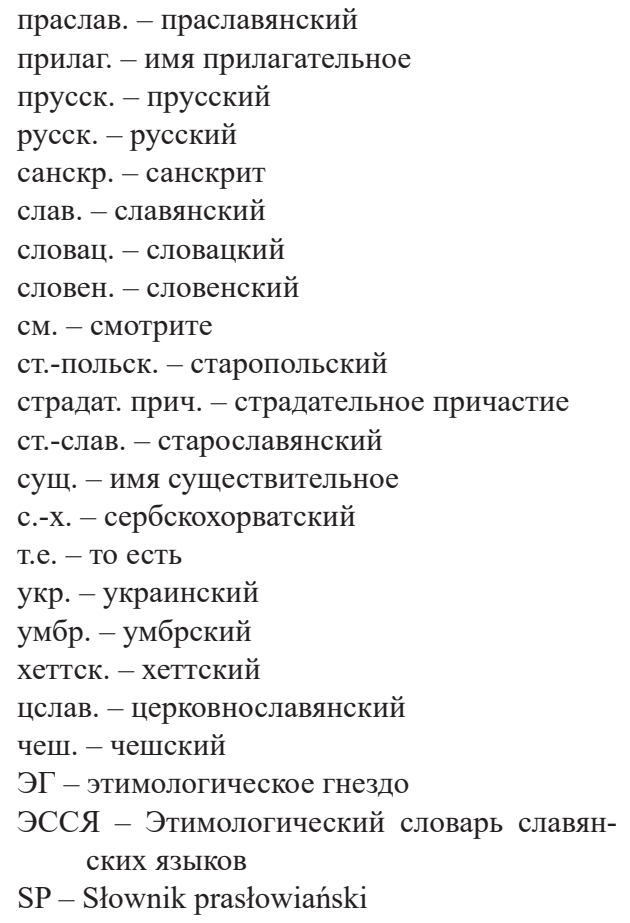

\section{Natalia Piataeva}

\section{THE ETYMOLOGICAL NEST *DATI IN THE SLAVONIC LANGUAGE: RECONSTRUCTION, WORD FORMATION, SEMANTICS}

(Summary)

The article presents the results of a study of vocabulary from Indo-European root *dō- in the Proto-Slavonic language.

As a result, the following was performed:

1) reconstruction of etymological nest with vertex *dati 'give; the process of transferring of an object to another person in relation to the pre-Slavic state based on the use of materials of etymological dictionaries comprising the later Slavonic language - «Etymological dictionary of Slavic» edited by O. Trubachyov and «Słownik prasłowiański» edited by F. Slavsky;

2) description of the methodology for etymological nests built by the type of a word-forming nest, principles of the making and design were developed by A. N. Tikhonov in "Word-formation dictionary of the Russian language";

3) lexicographical parameterization of an etymological nest in the form of a diagram, which shows the word-formation and semantic relations of the words;

4) description in terms of various aspects housing cognate words in terms of semantics, derivation, their morphemic composition and morphological characteristics; 
5) in the Slavonic nest, there are 4 semantic word-building centers, which underwent deetymologization in the old Russian language and formed the independent word-formation nests: verbial: *dati, *damъ 'give', and three nominal: *danь 'tribute to file' as the obligatory transfer of the object as a ransom fee, tax, *darb 'gift' as a voluntary transfer of an object as a gift, remuneration and a noun nomen acti *datja 'giving, bringing a gift'.

The author hopes that this list of major lexical associations in successive historical levels in the language development can play an important role in the system view on the formation and dynamics of the world picture of the native speakers of this language.

Keywords: etymological nest, Indo-European root, reconstruction, word formation, semantics, semantic-derivational center, deetimologization, ProtoSlavic language picture of the world.

\title{
ЭТИМОЛОГИЧЕСКОЕ ГНЕЗДО *DАТІ В ПРАСЛАВЯНСКОМ ЯЗЫКЕ: РЕКОНСТРУКЦИЯ, СЛОВООБРАЗОВАНИЕ, СЕМАНТИКА
}

\author{
(Резюме)
}

В статье представлены результаты изучения словарного корпуса индоевропейского корня *dō- в праславянском языке.

В результате было выполнено следующее:

1) реконструировано этимологическое гнездо с вершиной *Dati “процесс передачи объекта другому лицу’ по отношению к праславянскому лингвохронологическому уровню на основе использования материалов этимологических словарей, включающих лексику позднепраславянского периода - «Этимологический словарь славянских языков» под редакцией О. Н. Трубачёва и «Słownik prasłowiański» под редакцией Ф. Славского;

2) дано описание методики реконструкции этимологического гнезда, построенного по типу словообразовательного гнезда, принципы составления и матрица лексикографического представления которого были разработаны А. Н. Тихоновым в «Словообразовательном словаре русского языка»;

3) представлена схема этимологического гнезда, на которой показаны последовательные словообразовательные и семантические отношения между родственными словами;

4) дано разноаспектное - семантическое, морфемное и морфологическое - описание корпуса слов, образующих этимологическое гнездо;

5) в реконструированном этимологическом гнезде выявлено 4 семантико-словообразовательных центра, которые деэтимологизировались на древнерусском лингвохронологическом уровне и образовали самостоятельные словообразовательные гнёзда: глагольное *dati, *damъ 'давать' и три именных - *danь 'дань, подать как объект обязательной передачи в качестве выкупа, налога, дара', *darъ 'дар, подарок как объект добровольной передачи в качестве подарка, вознаграждения’ и существительное nomen acti *datja, обозначающее действие передачи дани, вручения подарка.

Автор надеется, что реконструированное в виде диахронического словообразовательного словаря этимологическое гнездо и разработанная схема (матрица) разноаспектного исследования и лексикографического представления крупных лексических объединений могут сыграть важную роль в системном описании динамики формирования картины мира носителей языка.

Ключевые слова: этимологическое гнездо, индоевропейский корень, реконструкция, словообразование, семантика, семантико-словообразовательный центр, деэтимологизация, праславянская языковая картина мира 